\title{
El ordenamiento territorial y la construcción de territorialidades negras en la región del Medio Atrato*
}

\section{The territorial ordering and the black territorialities' construction in the Middle Atrato region}

\author{
Sandra Patricia Martínez B.**
}

\section{Resumen}

Ofrece una interpretación de la actual organización espacial del territorio chocoano, a partir del análisis de la dinámica interacción que se produce entre las formas de territorialidad practicadas por las comunidades negras tradicionalmente asentadas en la región, el proceso de reivindicación terri torial y étnica liderado por el movimiento social de negritudes y la política oficial de ordenamiento territorial.

Tomando como unidad de análisis la cuenca media del río Atrato, el trabajo interpreta las relaciones que se construyen entre un medio físico-cuya biodiversidad acusa una enorme fragilidad ecosistémica-, los ambientes construidos de los hábitats ribereños y las formas de organización social, laboral y política de la sociedad negra.

* Síntesis del trabajo de grado titulado El Ordenamiento Territorial y la construcción de territorialidades negras en la región del Medio Atrato, presentado para optar al título de Magíster en Geografía, énfasis en Ordenamiento Territorial.

** Socióloga Universidad Nacional de Colombia. Magíster en Geografía, Énfasis en Ordenamiento Territorial. Correo e.: wuerazo@yahoo.com 
Pero además de un análisis descriptivo de las relaciones que las comunidades medioatrateñas tejen en el territorio, interesa analizar aquí los mecanismos de adaptación, transformación o resistencia de estas comunidades al modelo convencional de desarrollo, centrando el análisis en el discurso y las acciones del movimiento social de comunidades negras, que a través del proceso de titulación colectiva han permitido imaginar formas alternativas de desarrollo y de organización territorial.

Palabras clave: Organización espacial, Territorialidades negras, Ordenamiento Territorial, Movimiento social de negritudes.

\section{Abstract}

A chocoano territory present spatial organization's interpretation is offered, starting from the dynamic interaction's analysis that takes place between the forms practiced by the black communities traditionally seated in the region, the territorial and ethnic vindication's process led by the Negro social movement and the Territorial Reordering's official policy.

Taken the middle Atrato river's basin as an analysis unit, this paper interprets the relationships that are constructed between a physical mean, whose biodiversity accuses an enormous ecosystem fragility; the social atmospheres built by the black society's riverside habitats, and its social, labor and political organization's forms.

In addition to the communities relations' descriptive analysis in this territory, the interest is to analyze these communities adaptation, transfor mation or resistance's mechanisms facing the conventional development's model, centering the analysis in the black communities social movement's speech and actions, that through the collective land legal appropriation process, has allowed to imagine some development and territorial organization's alternative forms.

Key words: Spatial organization, Black territorialities, Territorial ordering, Negro Social Movement.

58 Sandra Patricia Martínez B. 


\section{Introducción}

El presente artículo plantea una interpretación de la actual organización espacial del departamento del Chocó, y de la región del Medio Atrato en particular, a través del análisis de las prácticas territoriales ejercidas por las comunidades negras, así como de los procesos de reconfiguración territorial que se han dado en la región en los últimos años.

Tras la abolición de la trata negrera impuesta por el régimen de dominación español, la población liberada, así como los cimarrones y mulatos, iniciaron un largo trasegar a través de los inhóspitos parajes de la selva chocoana, desarrollando creativas estrategias de adaptación a la selva pluvial tropical, que se presentaba como su nuevo espacio vital. El contacto con las culturas amerindias fue prolífico en cuanto al aprendizaje de las prácticas económicas, los patrones de asentamiento, el manejo ecológico del territorio y el mundo mítico y mágico-religioso.

A lo largo de más de tres siglos, los afrodescendientes desarrollaron un complejo conjunto de estrategias productivas, formas de poblamiento, relaciones espirituales con la naturaleza, rituales culturales y creencias, a través del cual territorializaron ríos, montes, ciénagas y colinas.

Caracterizadas por un manejo ecológico del entorno natural, por un sistema de propiedad regido por relaciones solidarias y fuertes lazos de parentesco y por una apropiación simbólica del espacio, las prácticas territoriales de estas comunidades pronto se vieron amenazadas por intereses foráneos que, movidos por el auge de diferentes ciclos extractivos, irrumpieron en los bosques para llevarse las especies silvestres demandadas en el mercado. La amenaza sobre la integridad territorial de las comunidades nativas se tornó inminente con la incursión de las empresas madereras que, desde mediados de siglo $\mathrm{xx}$, explotan indiscriminadamente los recursos forestales chocoanos.

Las concesiones otorgadas por el Estado a las grandes industrias madereras alentaron la lucha emprendida por los pueblos indígenas en torno a la defensa de su autonomía territorial, lucha a la que se sumaron las comunidades negras, en pos de garantizar la integridad del territorio como condición de existencia de estos pueblos.

La movilización de negros e indígenas en torno a la defensa de sus derechos étnicos y territoriales logró el reconocimiento de sus formas tradicionales de apropiación y uso del territorio en la Constitución de 1991, con la inclusión en su texto del Artículo Transitorio 55. Así pues, la nueva Carta Política marca un hito en la vida social y política del país. El reconocimiento del territorio nacional como un todo compuesto de muchas regiones y del carácter pluriétnico y multicultural del país cuestiona el criterio según el cual 
la política centralista veía en las diferencias culturales un obstáculo para forjar la pretendida unidad nacional.

En consonancia con estos dos principios, la nueva Constitución sienta las bases para la reestructuración del territorio nacional, definiendo como elementos constitutivos de dicho proceso el reconocimiento y protección de la diversidad étnica y cultural de la nación, el manejo y aprovechamiento racional de los recursos naturales, la puesta en marcha de formas de participación democrática y la intervención del Estado en la racionalización de la economía, con fines de desarrollo armónico y equitativo.

El asunto de la división del territorio, las disposiciones referentes a la organización territorial de la nación en entidades territoriales, el reconocimiento de la autonomía política y administrativa de tales entidades y el mandato de expedir una Ley Orgánica de Ordenamiento Territorial, entre otros aspectos, revelan, por lo menos, la voluntad formal del Estado de reorganizar sus espacios.

En materia de descentralización, se le daría un impulso decidido a la definición de las competencias y recursos de los entes territoriales, así como al reconocimiento de su autonomía política; procesos iniciados a mediados de la década de los ochenta con miras a recuperar la legitimidad del sistema político.
No obstante los avances alcanzados con la promulgación de la Constitución Política de 1991, aún es largo el camino por recorrer en la búsqueda de mecanismos conducentes a una ocupación y utilización del territorio compatible con las necesidades e intereses de la población. Esta situación es particularmente compleja en una región como la Pacífica, donde es posible identificar un conjunto de prácticas espaciales cuya lógica contrasta enormemente con la racionalidad occidental y estatal, representada en instrumentos legislativos como la Ley 388 de 1997, cuyos vacíos conceptuales comprometen su aplicabilidad real en la región. A esto se suma la desarticulación existente entre dicha normatividad y las formas de territorialidad propugnadas por el movimiento social de comunidades negras a través del proceso de titulación colectiva de sus territorios.

Dicha problemática refleja la actual situación territorial del Pacífico y evidencia, al mismo tiempo, cómo en todo proceso de ordenamiento territorial deben tenerse en cuenta las formas de apropiación territorial y manejo de los recursos practicadas por los diferentes grupos culturales en su interacción.

El ordenamiento territorial y la construcción de territorialidades negras en el medio Atrato constituye una aproximación crítica a esta problemática, a partir del análisis de las complejas relaciones que entrelazan las prácticas territoriales de las comunidades negras, el proceso de titulación colectiva

60 Sandra Patricia Martínez B. 
y el ordenamiento territorial visto desde la óptica estatal, para concluir que es posible imaginar formas alternativas de desarrollo y visiones distintas del ordenamiento territorial.

Metodológicamente, el trabajo se subdividió en tres grandes fases: la primera, la fase de trabajo de campo, en la cual se llevó a cabo la observación participativa de las actividades productivas, relaciones territoriales y pautas de poblamiento de las comunidades medioatrateñas, así como entrevistas en profundidad con pobladores de la región, representantes de organizaciones sociales de base y funcionarios oficiales y no oficiales. La segunda fase comprendió la revisión bibliográfica de la literatura existente sobre los temas referidos al ordenamiento territorial, las comunidades afrocolombianas, el proceso de titulación colectiva, los conceptos de espacio, territorio, lugar y organización espacial, así como los proyectos de ley, leyes y decretos que hacen parte de la normatividad de orden territorial vigente en la región, para lo cual se consultaron diferentes centros de documentación en las ciudades de Bogotá y Quibdó. La tercera fase correspondió a la sistematización de la información obtenida tanto de fuentes primarias como secundarias.

\section{Contenido de la investigación}

El trabajo consta de siete capítulos, en los cuales se aborda el tema de la organización espacial del territorio chocoano, profundizando en la dinámica territorial de la región del Medio Atrato desde la perspectiva conceptual y geohistórica, además de los antecedentes más significativos del problema de investigación y de una mirada de la situación territorial actual (ver mapa 1).

Las investigaciones sobre afrocolombianos son relativamente recientes en las ciencias sociales colombianas. Ellas se remontan a la década de los cincuenta del siglo $\mathrm{xx}$, pero tan solo en los años noventa los investigadores sociales se preocupan por elaborar conceptos y metodologías específicos para pensar la realidad del negro en Colombia, pudiéndose concluir que hoy en día no existe una orientación única en el abordaje de esta realidad.

El primer capítulo del trabajo constituye una aproximación a las diferentes corrientes epistemológicas que han alimentado los estudios sobre afrocolombianos en el país, y sugiere algunas de las preguntas de investigación que los geógrafos podrían contribuir a resolver. De igual manera, en este capítulo se hace un rápido recorrido por los antecedentes legales y algunas experiencias piloto en materia de Ordenamiento Territorial, previas a la expedición de la Ley 388 de 1997.

El segundo capítulo está dedicado a las categorías geográficas de lugar, territorio, espacio y organización espacial, haciendo especial énfasis en el lugar, como un concepto integrador de las fuerzas naturales y culturales. En un 

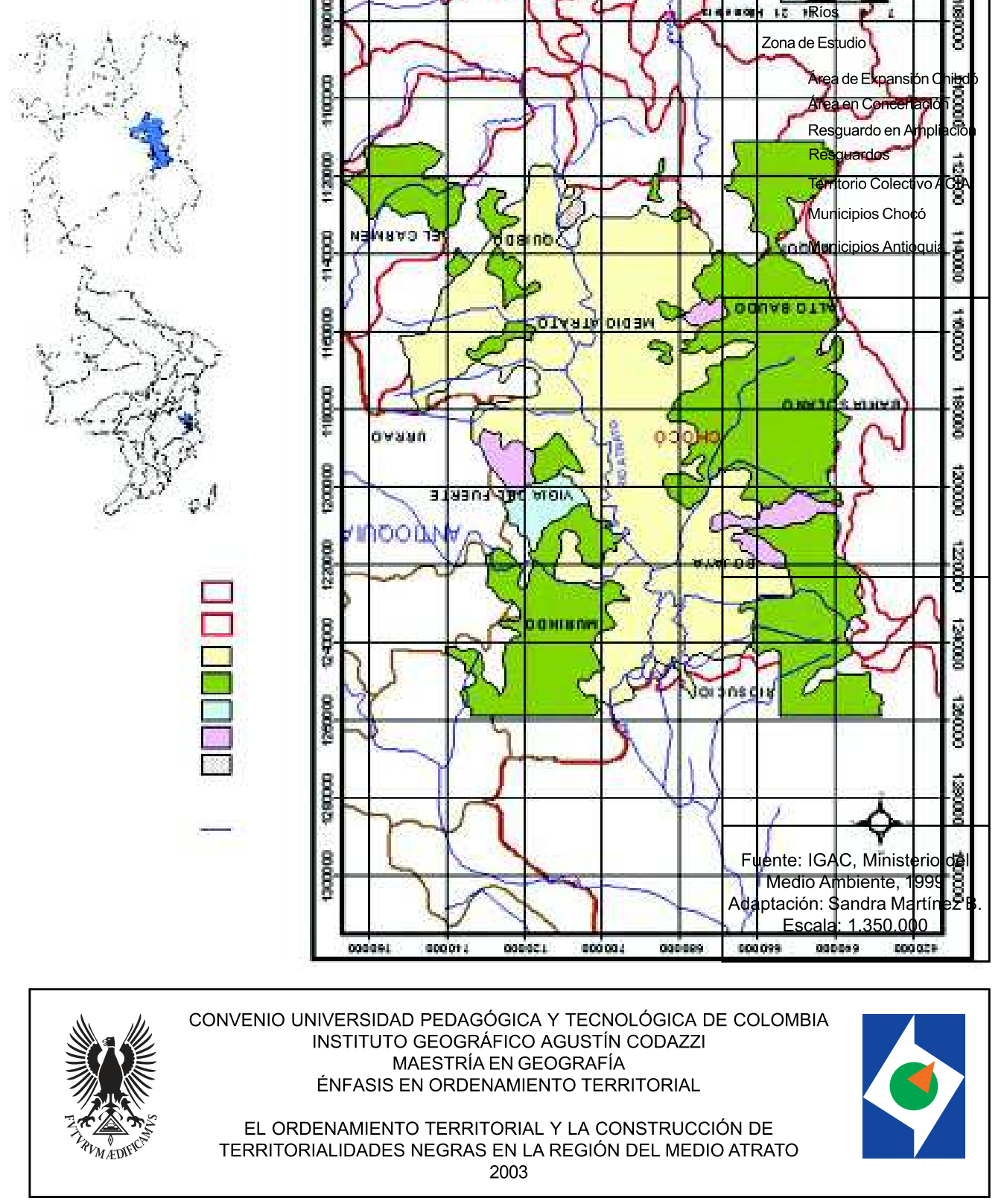

62 Sandra Patricia Martínez B. 
campo como el geográfico no se pueden pasar por alto las diferencias entre estos conceptos, ni las necesidades de reformulación teórica impuestas por las nuevas dinámicas espaciales acarreadas por el proceso de globalización. Este capítulo espera ser una contribución a dicho propósito.

Desde el periodo de conquista y colonización, el desarrollo histórico y espacial del departamento del Chocó se ha regido por una economía de enclave, sustentada en la extracción de los recursos renovables y no renovables de la región. Primero, con la intensiva explotación minera de los yacimientos existentes en el Alto Chocó, que caracterizó el periodo de colonización hispánica. Posteriormente, la fase de colonización agraria se vio dinamizada por el auge de distintos ciclos extractivos, que determinó el proceso de ampliación de la frontera agrícola, fenómeno que entra en crisis tras la escasez de recursos naturales para la explotación, dando lugar a nuevos procesos y actores sociales que jalonan el ordenamiento territorial actual. Las fases de la evolución geohistórica del departamento se describen en el tercer capítulo del trabajo.

El ambiente físico, como uno de los componentes por tener en cuenta en el análisis del espacio geográfico, es descrito en el cuarto capítulo, donde más que una descripción exhaustiva de las condiciones físicas del territorio chocoano, lo que se buscó fue establecer la relación entre estas condiciones, el ambiente construido y la sociedad que, a través de diversas estrategias productivas, patrones de asentamiento y formas de territorialidad le imprime una dinámica particular a los lugares.

En la región del Atrato medio subsisten prácticas milenarias de manejo espacial, como resultado de una profunda interacción entre los negros descendientes de la población africana trasladada a América y los grupos indígenas nativos (emberá y cuna), y de estos con el medio natural. Tales prácticas se reflejan en la concepción del territorio como un bien de uso, en claro contraste con la visión occidental, así como en la existencia de espacios de uso de apropiación colectiva, que se manifiesta en la pervivencia de formas solidarias de organización del trabajo y de normas consuetudinarias que regulan el acceso a la propiedad.

En el quinto capítulo se analizan los sistemas tradicionales de producción, las modalidades de apropiación y percepción territorial y las pautas de poblamiento, como los tres componentes fundamentales del proceso de construcción de territorialidades negras en el curso medio del río Atrato.

El sexto capítulo pretende documentar la situación territorial actual de la región a través del examen de la política oficial de ordenamiento territorial y su aplicación en la región a partir de dos procesos que se han venido produciendo de manera casi simultánea: 
la titulación de territorios de comunidades negras y la formulación y ejecución de Esquemas, Planes Básicos y Planes de Ordenamiento Territorial Municipales.

En el último capítulo se exponen las conclusiones del trabajo, sintetizando los principales resultados, logros y dificultades de la investigación, además de sugerirse algunas líneas de investigación en el futuro.

\section{La organización del territorio chocoano: una aproximación geohistórica}

Desde una perspectiva geohistórica, pueden distinguirse tres fases en el ordenamiento territorial chocoano: dominación colonial, colonización popular agraria y fase de organización espacial actual.

La primera fase, enmarcada dentro del régimen de dominación colonial, abarca aproximadamente tres siglos (ss. XVII-XIX) y se caracteriza por la conquista tardía del territorio y por un poblamiento intensivo alrededor de los principales enclaves mineros de la región.

Dentro de esta fase pueden identificarse, a su vez, tres momentos: el primero, de poblamiento exclusivamente aborigen; se extiende hasta las postrimerías del siglo XVII, cuando los conquistadores finalmente logran reducir a la población indígena; el segundo abarca el siglo xvIII, y se caracteriza por la instalación de "pueblos de indios" a lo largo del río Atrato y por la introducción de mano de obra esclava, y el tercer momento, que se inicia desde finales del siglo XVIII y se extiende hasta principios del siglo XIX, en el cual se registra la presencia de hábitats agrícolas de campesinos descendientes de la población esclavizada.

La implantación del sistema colonial en tierras chocoanas fue un proceso tardío con respecto al de otras regiones del país. Esta fase se caracterizó por una relación ambivalente entre la población aborigen y los colonizadores españoles, fluctuante entre el acercamiento y la confrontación abierta. La campaña catequizadora jugó un papel decisivo en la instauración definitiva de las instituciones coloniales en la región a finales del siglo xvII, que en adelante encaminaron sus esfuerzos a la explotación intensiva de los ricos yacimientos auríferos.

A diferencia de otras zonas mineras, la explotación aurífera en el Chocó se distinguió por el uso intensivo de mano de obra esclava, dadas las dificultades presentadas para el sometimiento de la población indígena. No obstante, desde finales del siglo xvIII confluyeron una serie de factores que condujeron a la quiebra definitiva del sistema esclavista, a mediados del siglo XIX, entre los cuales se cuentan: el abandono de la trata negrera por parte de Inglaterra como principal potencia

64 Sandra Patricia Martínez B. 
traficante, la crisis económica que atravesaban los hacendados neogranadinos, la manumisión espontánea, la compra de la libertad por parte del esclavo, la mezcla racial, la rebelión y el cimarronismo, a través de los cuales la población esclavizada obtenía su libertad, y el auge de las ideas independentistas.

La segunda fase, denominada por Aprile-Gniset y Mosquera (1998) Fase de colonización popular agraria, estuvo marcada por el proceso de colonización extensiva a lo largo de la red hidrográfica de la región, entre 1850 y 1940, aproximadamente. Asociado a diversos factores, como la liberación definitiva de los esclavos y el auge de diferentes ciclos extractivos, así como a distintas épocas de auge y retroceso en la explotación aurífera, dicho periodo se caracterizó por una intensa movilización de la población en busca de tierras para colonizar. Desde el Alto San Juan y Atrato, la población negra se desplazó, entonces, hacia la cuenca media de estos ríos y sus afluentes, hacia la zona costera, la región del Golfo de Urabá y la Serranía del Baudó.

De este modo se inició la colonización agrícola del territorio chocoano, con la incorporación de tierras vírgenes, primero a la explotación y recolección de frutos silvestres, y, posteriormente, al cultivo de productos como maíz, yuca, arroz, cacao, caña de azúcar y plátano, o a actividades como la pesca y la extracción maderera, incentivadas por la demanda de víveres y productos agroforestales por parte de ciudades como Quibdó, Barranquilla o Cartagena.

La fase de organización espacial actual del departamento, por su parte, empieza a configurarse a finales de la década de los cuarenta del siglo $\mathrm{xx}$, cuando el proceso de ampliación de la frontera agrícola entra en crisis, pues al tiempo que los recursos y tierras para explotar empiezan a escasear, aparecen en el escenario nuevos factores de desestabilización, tales como la incursión de agentes foráneos y las consiguientes transformaciones en la estructura de poder local, la instauración de sistemas de explotación intensiva de los recursos naturales y la incorporación de la población nativa a estas actividades.

Esta fase puede caracterizarse como un periodo bastante dinámico en términos de la estructura de poder local. Del dominio detentado por las antiguas familias esclavistas payanesas, marcado por un rígido sistema de exclusiones socioraciales, se transita hacia un reacomodamiento de la pirámide social, con la puesta en escena de nuevos sectores que, en diferentes momentos históricos, se reparten el poder político y económico en la zona: desde los comerciantes siriolibaneses, pasando por la clase política negra en ascenso y el colono paisa, hasta los grupos armados ilegales que se disputan actualmente el control territorial de algunas zonas estratégicas del Departamento. 
Y es precisamente el carácter profundamente dinámico de las relaciones de poder lo que hace del estudio genealógico de un territorio una empresa inagotable. En palabras de JoanEugeni Sánchez:

El hecho de que sobre el mismo espacio geográfico se hayan ido sucediendo los acontecimientos históricos, es un aspecto a considerar en la interpretación conflictiva de las relaciones sociales territorializadas. Por un lado, por el hecho de que un mismo territorio haya estado sometido a lo largo del tiempo a la ocupación y dominación de diversas sociedades con diversas culturasideologías, implica formas diversas de actuación sobre el territorio -rehistorización-. Pero también implica que cada forma posterior debe partir y remodelar una forma anterior, y así sucesivamente en un proceso genealógico imparable (1992: 37-38).

\section{La territorialidad entre las comunidades negras del medio Atrato}

En el Medio Atrato es palmaria la estrecha relación existente entre el entorno físico y la apropiación cultural del territorio -que se traduce en ambientes construidos de variable complejidad-, por un lado, y, por el otro, la sociedad que habita, explota $y$ transforma dicho entorno a través de sistemas tradicionales de producción, mediados no sólo por las relaciones económicas y las fuerzas productivas disponibles, sino también por ciertas lógicas culturales.

En efecto, en la estrategia adaptativa ejercida por el medioatrateño como mecanismo de sobrevivencia, además de las condiciones ofrecidas por el medio -que limitan o favorecen el desarrollo de diversas actividades productivas-, intervienen las relaciones de parentesco que, a través de un complejo sistema de normas y derechos fundados en la tradición, prescriben determinados roles sociales para los miembros de la parentela.

De ahí que una aproximación a los procesos de construcción de territorialidades en el Medio Atrato pasa necesariamente por el análisis de estos tres aspectos: el ambiente físico, como sustrato natural que, en principio, se constituye en un elemento diferenciador de los espacios geográficos; el ambiente construido, que se ha traducido en la transformación del espacio productivo en lugares de residencia, marcados por diferentes grados de complejidad, dependiendo de sus niveles de sedentarización y consolidación, y la sociedad afrodescendiente, que en su incesante viaje a través del tiempo y el espacio ha construido y renovado su identidad étnica dentro de un proceso permanente de interacción con disímiles grupos culturales, como el hispano, el indígena $\mathrm{y}$, en las últimas décadas, el interiorano.

A continuación se presentan los rasgos más sobresalientes de los sistemas tradicionales de producción, las pautas

66 Sandra Patricia Martínez B. 
de poblamiento y las formas de territorialidad, en tanto componentes fundamentales del ambiente construido por la sociedad afroatrateña.

\subsection{Sistemas tradicionales de producción}

La estrategia económica practicada por las comunidades negras del Medio Atrato se puede caracterizar como una economía doméstica, cuya producción está orientada básicamente al consumo, con generación de pequeños excedentes que son comercializados o intercambiados para la adquisición de los productos de primera necesidad que la unidad familiar no puede producir.

Además de estar orientada a la reproducción de la familia, es característico de este tipo de economías que la producción descanse fundamentalmente en la utilización de fuerza de trabajo familiar, con medios de producción de propiedad de la unidad familiar y un grado de tecnificación mínimo.

No menos importante es el peso de las relaciones de parentesco en la producción, en el acceso a la tierra y los recursos naturales, en el poblamiento, así como en la vida cotidiana del medioatrateño. En torno a la familia extensa se construye una compleja red de relaciones fundadas en la solidaridad y el favor recíproco, así como en el cumplimiento de ciertas obligaciones por parte de los miembros de la parentela, dadas por el rol que cada uno de ellos debe desempeñar dentro del sistema de parentesco (Valencia y Leesberg, 1987), lo cual se refleja en la división del trabajo dentro del grupo familiar, que le asigna a cada uno de sus integrantes determinadas labores de acuerdo con el sexo o la edad.

Las relaciones de solidaridad existentes entre los miembros de la parentela se extienden a toda la comunidad y se manifiestan en el intercambio de bienes y servicios, así como en formas solidarias de trabajo, como la cuadrilla, la mano cambiada y el trabajo colectivo ${ }^{1}$.

Los sistemas tradicionales de producción en el medio Atrato se distinguen por su versatilidad adaptativa, es decir, por la capacidad del campesino para optar por una u otra alternativa productiva de acuerdo con las condiciones que el medio le ofrece, con la disponibilidad de mano de obra y de recursos y con la distribución del

\footnotetext{
1 La cuadrilla reúne a diez o doce miembros de diferentes núcleos familiares en torno al trabajo en la mina. La dirección y coordinación del trabajo recae en el "jefe de cuadrilla", que por su liderazgo y aceptación dentro de la comunidad es obedecido por los demás integrantes del grupo. La mano cambiada consiste en el intercambio de trabajo entre personas que van a desarrollar una misma labor, sin que medie una remuneración en dinero; se organizan grupos de diez personas, aproximadamente, que van rotando el trabajo en la parcela de cada uno de sus integrantes hasta que todos se han beneficiado del trabajo en común. El trabajo colectivo está orientado básicamente a resolver necesidades de interés comunitario, como la construcción de la escuela, el puesto de salud, la capilla o la pavimentación de las calles del pueblo.
} 
tiempo a lo largo del ciclo anual (Valencia y Leesberg).

Ello supone un profundo conocimiento del entorno natural, como resultado de la experiencia acumulada durante más de tres siglos y transmitida de generación en generación. El nativo conoce su entorno y los diferentes ritmos naturales que lo rigen, como el régimen de lluvias y los ciclos lunares, y a partir de este conocimiento determina la estrategia productiva por implementar. Esto le permite la optimización de la mano de obra disponible, así como garantizar el sustento alimenticio de la familia durante buena parte del año.

Es así como el funcionamiento del sistema depende de un marco temporal y espacial determinado por factores climáticos y periodos productivos de la naturaleza: los periodos secos son aprovechados para el corte de madera, la limpieza del terreno y la preparación de suelos, la construcción de viviendas y de herramientas de trabajo y la pesca intensiva, ya que la subienda coincide con estos periodos, que se extienden de diciembre a abril, aproximadamente. Al comenzar las lluvias se siembra, se recoge la cosecha de algunos frutos, como el chontaduro y el almirajó, se caza y se saca madera aprovechando el aumento del nivel de los ríos y afluentes.

De manera consistente con lo anterior, los sistemas tradicionales de producción del Medio Atrato se caracterizan tanto por la constante rotación de actividades de acuerdo con las variaciones del ciclo natural, como por la complementariedad de actividades económicas. La unidad familiar distribuye su tiempo de tal manera que pueda dedicarse simultáneamente a la mayor diversidad de actividades posible: agricultura, minería, extracción forestal, recolección de frutos, cacería, pesca, labores artesanales y domésticas.

Es posible afirmar, entonces, que la estrategia económica del medioatrateño está encaminada a lograr la mayor diversidad de productos posible, con el fin de garantizar la producción alimentaria en los meses de escasez, basándose en una división del trabajo que permita explotar los diferentes recursos disponibles y contar con mano de obra suficiente (Valencia y Leesberg).

\subsection{Los ambientes construidos del medio Atrato}

La relación ambiente físico-sociedad tiene en el medio Atrato una expresión directa y tangible en los espacios construidos de los hábitats ribereños, producto de la transformación paulatina del espacio productivo en lugares de residencia. Con la presencia y el trabajo del hombre, el espacio ha dejado de ser solamente natural, para convertirse en espacio social, en el cual la sociedad afroatrateña se recrea y reafirma su modo de vivir con respecto a la naturaleza y a su misma sociedad.

68 Sandra Patricia Martínez B. 
Como resultado de un patrón de ocupación territorial extensivo a lo largo de los ríos, en el Atrato medio se observa hoy un sistema de aldeas fluviales diseminadas en las orillas de ríos y quebradas. En efecto, el río se constituye en el eje articulador del poblamiento en la región, donde se ha configurado un patrón de asentamiento lineal y ribereño que se corresponde con el tipo de economía practicada por las comunidades negras.

En su gran mayoría, estas aldeas surgen a partir de la sedentarización de colonos agrícolas en sus lugares de trabajo, que son transformados en sitios de residencia; crecen y se expanden al mismo ritmo del crecimiento familiar y, con frecuencia, desaparecen, se estancan o trasladan para fortalecer otros asentamientos de mayor dinamismo.

Tanto el surgimiento como la permanencia de los hábitats atrateños están íntimamente ligados a las actividades productivas y su importancia dentro de la estrategia económica del campesino. Así, la actividad principal, generalmente, define la consolidación del lugar de residencia familiar durante gran parte del año; las actividades complementarias le exigen al productor el levantamiento de viviendas temporales o 'trabajaderos', donde permanece determinadas temporadas, mientras que las labores adicionales, por su carácter esporádico, propician el constante desplazamiento del campesino entre su lugar de residencia y el sitio de trabajo, sin requerir la construcción de ranchos temporales.

Así como las actividades, los productos agrícolas también condicionan la permanencia o movilidad del campesino. El prolongado ciclo del plátano, por ejemplo, propicia la instalación en su entorno inmediato de una vivienda estable, mientras que el carácter temporal del arroz requiere la construcción de 'trabajaderos', ya sea en el mismo sitio del cultivo o en parcelas cercanas.

De tal suerte que los ciclos entre la siembra y la cosecha determinan la presencia de la familia en el cultivo o fuera de él y, por ende, su permanencia y sedentarización en los lugares, que inicialmente se da de manera dispersa a lo largo de los cursos fluviales.

No obstante, la sedentarización residencial en el lugar de trabajo empieza a ser un obstáculo cuando las actividades productivas se diversifican, exigiendo la circulación entre parcelas agrícolas distantes de la residencia, o entre el lugar de producción y los centros de consumo. Ello conlleva una división social del trabajo y, por ende, una división del espacio geográfico a partir de la separación entre el hábitat productivo y el hábitat residencial, surgiendo así la aldea de colonos agrícolas (Aprile-Gniset y Mosquera: 39).

De esta manera se va conformando un tipo de hábitat nucleado, habitado por agricultores que trabajan sus parcelas 
en las inmediaciones del río y donde las relaciones de solidaridad y cooperación juegan un papel de primer orden.

No obstante, los procesos actuales de integración a las economías de mercado, la colonización externa, las migraciones hacia los centros urbanos, entre otros factores, están generando transformaciones profundas en el patrón tradicional de asentamiento propio de las comunidades negras. Entre estos factores, el desplazamiento forzado ha jugado un papel determinante, no solo en el cambio de las pautas de poblamiento, sino también en la calidad de vida y bienestar de la población, que se ha visto sometida además a diversas medidas violatorias de sus derechos, tales como: restricción al paso de alimentos, medicinas y combustible; retenes que impiden la libre movilización; limitación de los lugares de trabajo en algunos afluentes y quebradas; interferencia en el ritmo de las actividades productivas y de mercadeo, entre otras.

\subsection{La territorialidad afroatrateña}

Entre las comunidades negras medioatrateñas, la apropiación subjetiva del territorio juega un papel central, en claro contraste con la territorialidad ejercida por otros agentes sociales, llámense planificadores estatales o sectores empresariales, cuya apropiación territorial se basa fundamentalmente en criterios objetivos, tales como las delimitaciones político-administrati- vas o el aprovechamiento comercial, respectivamente.

Entre los afroatrateños predomina la concepción del territorio como un espacio vital, por encima de su consideración como un bien inmueble de intercambio comercial. Así, la relación de estos pobladores con el territorio no se limita al aprovechamiento económico, sino que es también una relación simbólica, atravesada por visiones y prácticas ecológicas en armonía con la naturaleza.

El territorio hace parte de la cosmovisión de los afrocolombianos $\mathrm{y}$, como tal, es un componente fundamental de la identidad cultural de estos grupos. En él se plasman sus imaginarios, que se concretan en el ámbito del trabajo y de las relaciones sociales y familiares, en una interacción dinámica entre la apropiación material y simbólica del espacio geográfico.

Entre las comunidades negras del Pacífico coexisten la propiedad individual o familiar y la apropiación o usufructo colectivo del territorio. La delimitación de estas formas de propiedad descansa en la parentela, cuya posesión ancestral determina su propiedad sobre un tramo del río. Cada parentela o partida tiene delimitada su propiedad, que se extiende desde el "frente" u orilla del río hacia adentro hasta tropezar con un límite natural, como una montaña o un caño. Estos linderos se conocen como "fondo" o "centro" y tienen como finalidad garantizar a los descendientes sus propias parcelas para trabajar.

70 Sandra Patricia Martínez B. 
La propiedad familiar sobre el "fondo" o "centro" no riñe con el usufructo colectivo que de él hace el resto de la comunidad; esta aprovecha los recursos del bosque a través de la cacería, la recolección, el cateo de minas y el corte de maderas en las áreas de bosque, así como los recursos pesqueros en las ciénagas y ríos.

Estas áreas, conocidas regionalmente como "respaldo" o "bosque comunitario", carecen de delimitaciones, es decir, cualquier persona de la comunidad puede acceder libremente a los recursos que allí se encuentran, siempre y cuando se acoja a las normas reconocidas consuetudinariamente.

La territorialidad afroatrateña está regida, entonces, por las normas y convenciones comunitarias, sobre las cuales se erige un derecho consuetudinario fundado en el respeto a la propiedad del otro y en la utilización racional de los recursos comunitarios. Tales convenciones descansan en la oralidad, que tradicionalmente ha regulado las relaciones de propiedad entre estas comunidades. Tanto la posesión de la tierra, basada en las mejoras incorporadas a ella, como cualquier otra transacción están mediadas por acuerdos verbales que conservan su vigencia durante años, incluso durante varias generaciones.

Lo anterior demuestra cómo entre las comunidades negras la tierra es fundamentalmente un bien de uso; la solidaridad y la cooperación se anteponen a cualquier finalidad de lucro. Las transacciones territoriales, que en otro tipo de sociedades tienen un carácter eminentemente comercial, aquí constituyen la máxima expresión del favor recíproco.

No obstante, las normas consuetudinarias de estas comunidades se han visto constantemente vulneradas por otras racionalidades, incluyendo la misma legislación nacional, que durante más de cuarenta años desconoció la posesión ancestral de las comunidades negras sobre el litoral pacífico. Así mismo, la incursión de agentes foráneos ha lesionado seriamente la autonomía de estas comunidades sobre el manejo de sus territorios y de los recursos naturales renovables y no renovables existentes en ellos, especialmente en materia de explotación minera y forestal.

\section{Situación territorial actual}

La comprensión de la dinámica territorial actual de la región Pacífica pasa necesariamente por la revisión de la legalidad que desde el Estado se ha construido para caracterizar y ordenar la región. Si bien las leyes en sí mismas no determinan los procesos de apropiación territorial del espacio geográfico, sí expresan una manera particular de entenderlo, configurando un marco de acción de las relaciones entre los actores sociales, el territorio y los recursos que en él se encuentran. 
Desde la tercera década del siglo XIX, la región Pacífica es caracterizada como un área de bosque natural en tierras baldías que es necesario proteger a través de la reglamentación del uso y aprovechamiento de los recursos del bosque. Para ello, el Estado colombiano ha expedido una copiosa legislación agraria y forestal en materia de administración de baldíos, definiendo diferentes mecanismos para el acceso a la explotación de los recursos, tales como la concesión y el arrendamiento, así como la clasificación vigente de los bosques naturales.

Mediante Ley 2. da de 1959, la región Pacífica es declarada Zona de Reserva Forestal Protectora; declaratoria que a la vez que limita las posibilidades de acceso a la propiedad individual y colectiva a las comunidades negras ancestralmente asentadas en este territorio, estimula los procesos de colonización y explotación industrial de los recursos forestales a través de la figura de la sustracción.

Dos años más tarde, la Ley de Reforma Agraria (Ley 135 de 1961) faculta al Incora para sustraer áreas dentro de las zonas de reserva forestal, estimulando la colonización de campesinos nativos y foráneos, que en treinta años de vigencia de esta ley lograron legalizar su propiedad sobre un $18 \%$ de la superficie total de la región.

A esto se sumó la creación, ampliación y saneamiento de resguardos indígenas, la creación de ocho Parques Nacionales Naturales en la Cuenca del Pacífico, la constitución de once reservas naturales especiales con diferentes fines y la asignación de perímetros urbanos a cada uno de los 43 municipios existentes en toda la región, procesos todos que reducían cada vez más las posibilidades de las comunidades negras de acceder a sus territorios.

Hasta 1993, año en el cual entra en vigencia la Ley 70, el Incora había legalizado 137 resguardos indígenas en el Pacífico, con una extensión de 1.681.963 hectáreas, que cubren a 9.673 familias; había tramitado 44 títulos más con un área de 324.288 hectáreas, para un total de 181 resguardos; había atendido solicitudes de ampliación y constitución sobre una extensión aproximada de 500.000 hectáreas, para un total de 2.506.251 hectáreas, a favor de 12.246 familias indígenas (Incora, 2001: 8), y había reservado un área de 140.205 hectáreas para los perímetros urbanos de los municipios de la región (ver mapa 2).

Así entonces, a principios de la década de los noventa, cerca del cincuenta por ciento del territorio del Pacífico había sido titulado a favor de diversos intereses públicos y privados, desconociéndose la posesión ancestral de las comunidades negras sobre el territorio, cuyas formas de apropiación espacial no eran visibles para un Estado que veía en la explotación del suelo a través del establecimiento de plantaciones y sementeras, de la ocupación con

72 Sandra Patricia Martínez B. 

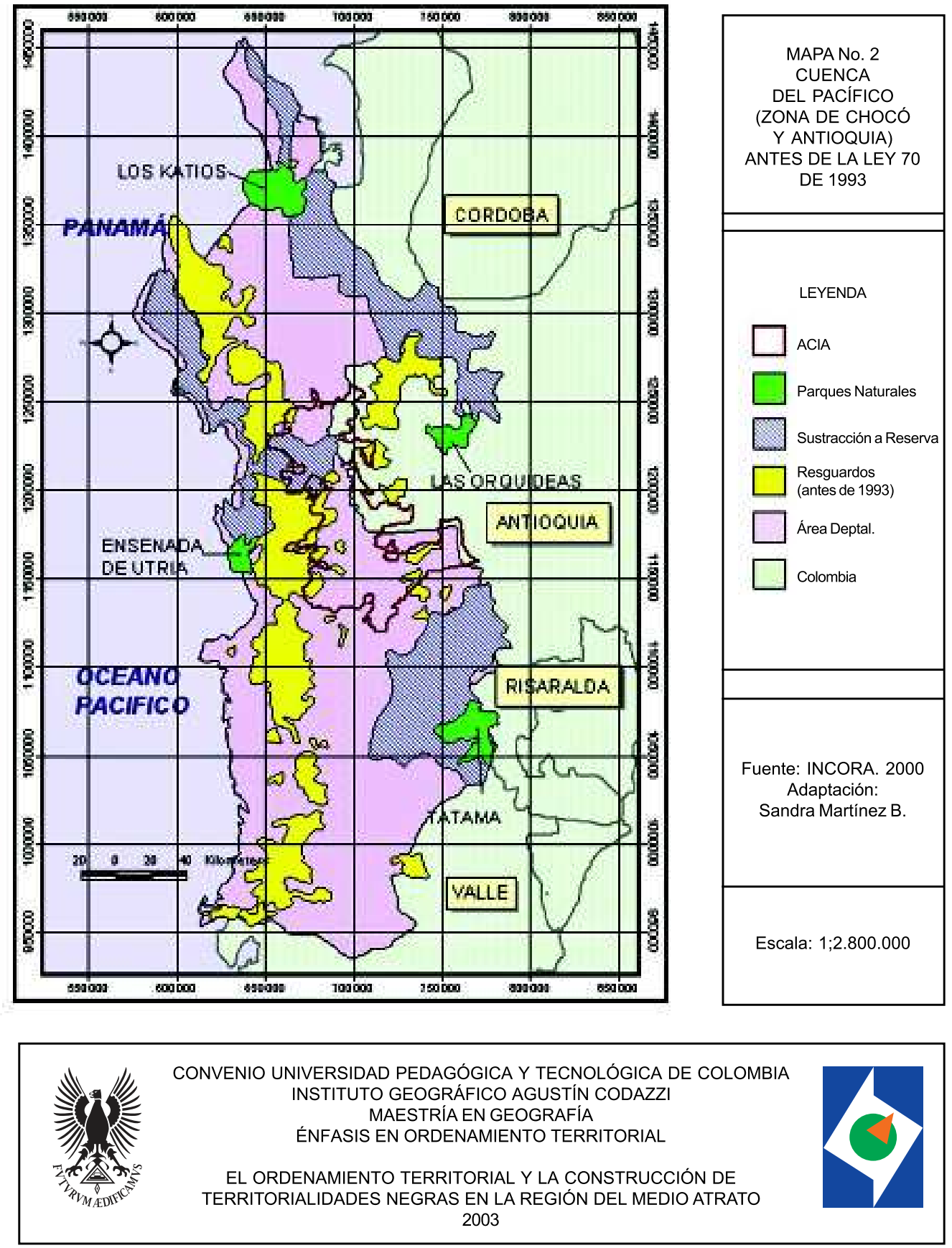

Perspectiva Geográfica Núm. 1 1, 2005 
ganado o el cerramiento, la única evidencia de posesión y propiedad sobre el territorio.

\subsection{El movimiento social de comunidades negras: hacia una redefinición de la región}

El surgimiento y consolidación del movimiento social de comunidades negras se produce en un momento coyuntural, marcado por dos hechos: la intensificación de la apertura de la nación a los mercados internacionales, especialmente hacia las economías de la cuenca Pacífica, desde la década de los noventa, y el reconocimiento de los derechos étnicos de los grupos minoritarios en el texto constitucional de 1991.

La reivindicación de los derechos étnicos y territoriales por parte del movimiento negro constituye un espacio de resistencia al proyecto modernizador agenciado por el Estado y el capital en la región Pacífica, a partir de los planes de expansión urbana, construcción de infraestructura e intensificación de la agroindustrialización.

La defensa del territorio aparece como un elemento central en la construcción identitaria del movimiento de comunidades negras, ya que este es concebido como un espacio vital para la creación y recreación de las prácticas culturales, sociales y económicas de estas comunidades. En el territorio se entrelaza un complejo entramado de significaciones y prácticas asociadas con los sistemas tradicionales de producción, las pautas de poblamiento y ciertas formas de apropiación del espacio geográfico en relación armónica con el medio físico.

Una de las organizaciones de base de mayor trayectoria en la lucha por el reconocimiento de los derechos étnicos de las comunidades negras es la Asociación Campesina Integral del Atrato -ACIA-, que, junto con otras organizaciones regionales negras e indígenas, lidera los procesos de discusión y movilización en torno a la reivindicación de los derechos étnicos y territoriales de estos grupos, que precedieron la Asamblea Nacional Constituyente.

Gracias a la presión ejercida por las comunidades negras e indígenas a través de sus organizaciones de base, se logra la inclusión del Artículo Transitorio 55 en el texto de la nueva carta constitucional, que dos años más tarde se materializa en la Ley 70 de 1993, mediante la cual se reconoció a las comunidades negras el derecho a la propiedad colectiva sobre los territorios que han venido ocupando ancestral e históricamente en la cuenca del Pacífico.

En octubre de 1995 se expide el decreto 1745 reglamentario del capítulo III de la Ley 70, en el cual se definen los Consejos Comunitarios como máxima autoridad de administración interna dentro de los territorios de comunidades negras, sus organismos de

74 Sandra Patricia Martínez B. 
administración y sus funciones, el procedimiento por seguir para la titulación colectiva, así como los mecanismos para el manejo y administración de las tierras tituladas.

Es así como desde 1996 se vienen expidiendo títulos de propiedad colectiva para las comunidades negras; hasta abril de 2003 se habían titulado 4.555.383 hectáreas, correspondientes a 122 títulos colectivos, a favor de 1.922 comunidades negras (Incora, 2003: 1-6), (ver mapa 3).

\subsection{El proceso de titulación y administración de los territorios de comunidades negras: nuevos significados y prácticas del ordena- miento territorial}

En ejercicio de sus derechos territoriales, las comunidades negras del $\mathrm{Pa}-$ cífico se encuentran agenciando un proceso de reordenamiento territorial, dentro del cual son las comunidades mismas, desde sus percepciones y prácticas consuetudinarias de apropiación espacial, las que están definiendo los mecanismos para el ejercicio de su territorialidad.

Si bien el proceso de titulación legal de territorios de comunidades negras prácticamente está resuelto, es importante tener en cuenta que no se agota en el trámite jurídico de la expedición del título, pues exige también garantizar herramientas que posibiliten la autonomía y autogestión de estas comunidades sobre sus territorios.
Así, el proceso de titulación colectiva plantea nuevas situaciones problemáticas, que requieren una respuesta decidida de los Consejos Comunitarios, como entes encargados de la administración interna de estos territorios, así como un proceso de adecuación institucional y legislativa del Estado, que supone la descentralización del poder y el dominio real de tales Consejos en el ámbito local.

A finales de 1997, el Consejo Comunitario Mayor del Medio Atrato recibe el título colectivo sobre una extensión de 695.254,2 hectáreas, correspondientes al área de influencia de la organización, que agrupa 120 Consejos Comunitarios Locales. Partiendo de la experiencia organizativa de la ACIA, es posible identificar cuatro tipos de situaciones conflictivas derivadas de este nuevo proceso de ordenamiento territorial.

En primer lugar, los conflictos en torno a la administración y manejo de los recursos, donde la Ley 70 y la administración de los territorios colectivos, ejercida por los Consejos Comunitarios, son percibidos como un obstáculo al libre aprovechamiento de tales recursos, deviniendo en el incumplimiento de los reglamentos internos por parte de muchas comunidades.

Esta situación tiene que ver con la crisis de los sistemas tradicionales de producción en algunos sectores, asociada a la presión demográfica sobre unos recursos cada vez más escasos, así 

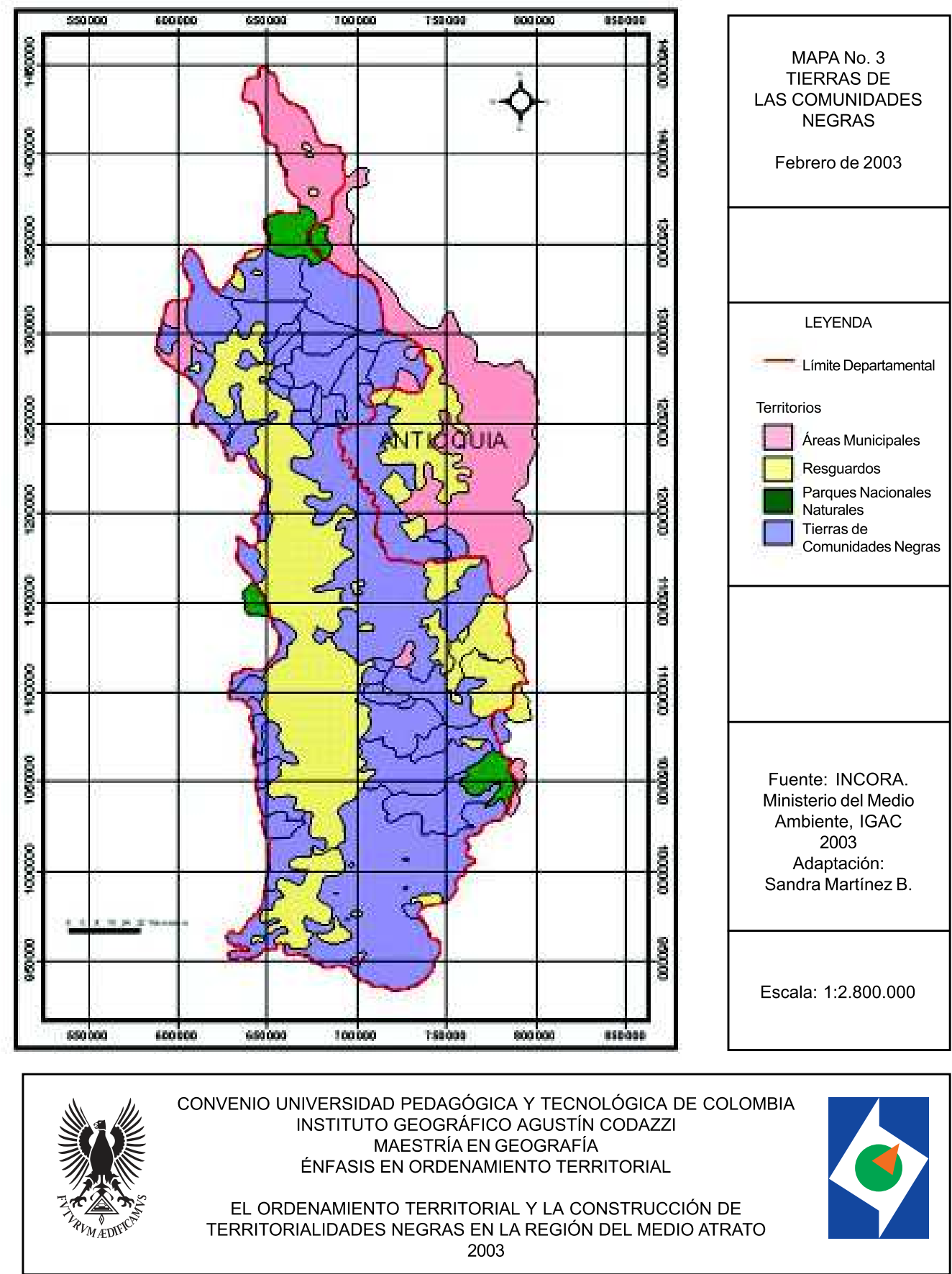

76 Sandra Patricia Martínez B. 
como a las nuevas necesidades y aspiraciones de los pobladores, que los han llevado a integrarse de manera creciente a las redes de mercado. Asimismo, el hecho de que la situación jurídica del territorio esté prácticamente resuelta no significa que las presiones externas sobre él hayan desaparecido.

En segundo lugar, se han presentado conflictos alrededor de la delimitación de los espacios comunales y de usufructo familiar, a cargo de los Consejos Comunitarios, a lo que se suman dificultades con algunas familias que con anterioridad a la expedición del título colectivo habían legalizado sus propiedades.

La debilidad organizativa de algunos Consejos Comunitarios y su consecuente falta de legitimidad entre las comunidades constituyen la tercera situación conflictiva asociada al proceso de titulación colectiva. Entre los factores que explican esta situación pueden señalarse: la falta de arraigo del Consejo Comunitario como forma de autoridad entre las comunidades, la creciente incorporación de los nativos al mercado de productos mineros y forestales, que reduce el margen de acción de los Consejos, y el bajo grado de conciencia del problema territorial por parte de algunas comunidades que se mantuvieron al margen del proceso organizativo liderado por la asociación.

En cuarto, y último lugar, es preciso señalar los conflictos intraétnicos, ya sea por la delimitación de los ámbitos territoriales de diferentes Consejos Comunitarios o por la inclusión de comunidades negras en contra de su voluntad dentro del título colectivo, y los conflictos interétnicos, entre comunidades negras e indígenas, tanto por la delimitación de territorios como por el uso de recursos naturales por un grupo en territorios del otro.

A pesar de los conflictos señalados, la reglamentación para el uso y aprovechamiento de los recursos naturales se ha constituido en un mecanismo de control a la explotación indiscriminada de estos, además de aumentar la autonomía de las comunidades en el manejo de su territorio.

\subsection{Los límites de la Ley de Desarrollo Territorial}

Al lado del proceso de titulación de territorios colectivos a las comunidades negras, está la implementación de la Ley 388 de 1997, como factor transformador de las relaciones territoriales en la región. No obstante, más que el estado de avance en la formulación e implementación de los planes de ordenamiento en la región, lo que interesa aquí es una aproximación crítica a los contenidos, alcances y viabilidad de la Ley 388.

Haciendo una lectura de la norma, se descubren una serie de aspectos que resultan conflictivos cuando se piensa en su aplicación concreta y en el impacto real que pueda tener en una 
región como la Pacífica. Quizá muchas de estas limitaciones tengan que ver con el carácter de la ley en tanto Ley de Desarrollo Territorial y no de Ordenamiento Territorial. Aparentemente un juego de palabras, esta diferenciación tiene importantes repercusiones en términos de los alcances y responsabilidades de la norma. Si bien es cierto en ella se definen objeto, principios y competencias del ordenamiento territorial, sus objetivos están orientados hacia la armonización de la dimensión territorial con las políticas de desarrollo, y no a la reorganización del territorio nacional, que sería competencia de la Ley Orgánica.

Hecha esta aclaración, se pasará, entonces, a examinar las referidas limitaciones de la ley.

La primera, y tal vez más importante de ellas, es la desarticulación existente entre el ordenamiento territorial derivado de la Ley 70 de 1993, por un lado, y aquel que se promulga con la Ley 388 , por el otro. Basta con una lectura de esta última ley para darse cuenta de que en ella no se contemplan los territorios colectivos de negros e indígenas, ni mecanismos de participación que puedan ser utilizados por los habitantes de estos territorios en la formulación de los planes de ordenamiento territorial municipales, cuando una parte significativa de los municipios del Pacífico ha adquirido, casi en su totalidad, la forma de titulación colectiva de Territorios de Comunidades Negras o bien de resguardos indígenas.
La segunda gran limitante de la Ley tiene que ver con su concepto de territorio, que obedece a un criterio eminentemente político-administrativo, con un marcado énfasis en la entidad municipal como eje del proceso de ordenamiento territorial. Naturalmente, esta noción, centrada en el ámbito jurisdiccional, riñe con los referentes espaciales de las comunidades negras, cuyo sentido de adscripción territorial nada tiene que ver con su pertenencia a uno $u$ otro municipio.

Así mismo, la pretensión de reorganizar el territorio con base en delimitaciones jurídicas resulta totalmente incongruente con la delimitación de los territorios de comunidades negras derivada de la puesta en práctica de la Ley 70 de 1993, donde el criterio principal que ha orientado este proceso es la pertenencia a la cuenca hidrográfica, la cual, por su misma naturaleza física, sobrepasa en mucho los límites municipales o departamentales.

Íntimamente ligada a la noción de territorio implícita en la ley, está la concepción misma de ordenamiento territorial, caracterizada por un marcado determinismo físico, en la medida en que se parte de considerar las acciones político-administrativas y de planeación física como los instrumentos por excelencia para orientar el desarrollo del territorio:

El ordenamiento del territorio municipal y distrital comprende un conjunto de acciones político-

78 Sandra Patricia Martínez B. 
administrativas y de planeación física concertadas, emprendidas por los municipios o distritos y áreas metropolitanas, en ejercicio de la función pública que les compete, dentro de los límites fijados por la Constitución y las leyes, en orden a disponer de instrumentos eficientes para orientar el desarrollo del territorio bajo su jurisdicción y regular la utilización, transformación y ocupación del espacio, de acuerdo con las estrategias de desarrollo socioeconómico y en armonía con el medio ambiente y las tradiciones históricas y culturales (Ley 388/97).

La pretensión de regular la utilización y ocupación del espacio a través de su transformación física pasa por ingenua, si se tiene en cuenta la complejidad social de regiones como la Pacífica, donde confluyen territorialidades distintas y, si se quiere, opuestas entre sí, dadas por la diversidad étnica, cultural y de clase que caracteriza la sociedad regional. Ello sin contar con las profundas transformaciones territoriales que está desatando el conflicto armado en la región.

A esto se suma el marcado énfasis de la Ley en el Ordenamiento Urbano, que en parte podría explicarse por su origen como instrumento legislativo que modifica la Ley 9 de 1989, más conocida como Ley de Reforma Urbana. Sin embargo, la denominación de la norma como Ley de Desarrollo Territorial genera expectativas que trascienden los espacios urbanos y que la ley, tal y como está concebida, no está en condiciones de satisfacer.
El sesgo urbano de la Ley 388 de 1997 se evidencia en el vasto conjunto de herramientas técnicas y jurídicas que la norma dispone para la planificación y gestión del suelo urbano, el cual contrasta notoriamente con una pobre incorporación de los espacios rurales. La ley presenta, entonces, un limitado desarrollo normativo para afectar el desarrollo rural, y, por ende, su eficacia en tanto instrumento regulador del ordenamiento del territorio nacional es más que cuestionable.

Si bien no puede desconocerse el acelerado proceso de urbanización al que se ha visto abocado el país en las últimas décadas, y que evidentemente requiere de políticas encaminadas a la reorganización de estos espacios, tampoco es admisible que se privilegie la cuestión urbana sobre la rural, menos si se tiene en cuenta que Colombia podrá ser un país poblacionalmente urbano, pero territorialmente sigue siendo rural. De manera, pues, que la Ley 388 se constituye en un instrumento eficaz para la organización de ciudades medianas y grandes, no así para regiones fundamentalmente rurales como la Pacífica.

Es más, si lo que se busca es el desarrollo armónico de los territorios urbanos y metropolitanos, debe pensarse también en la solución del problema agrario, en tanto componente fundamental de la realidad social concebida como una totalidad, donde la separación misma de lo rural y lo urbano no es más que puramente analítica. 
Esta última cuestión introduce otra de las falencias de la Ley de Desarrollo Territorial: se trata de la ausencia de una propuesta donde la redistribución equitativa de la propiedad se plantee como el fundamento mismo del proceso de reorganización territorial. En este sentido, la norma se queda en el planteamiento de reformas parciales sobre el uso del suelo, sin proponer alternativas de solución al problema agrario del país, que amplios sectores de la sociedad reclaman desde hace ya mucho tiempo. Cabe entonces la pregunta que un grupo de investigadores de la Universidad Nacional se formula en torno a la eficacia de la Ley: “¿Por qué se produjeron tantas expectativas frente a los POT cuando no se ve ninguna perspectiva de cambio social?" (Brand et al., 2001: 13).

El desconocimiento de las territorialidades negras e indígenas, el determinismo físico y político-administrativo, el sesgo urbano y la ausencia de propuestas de solución al problema de la tenencia de la tierra, que caracterizan la Ley 388, pueden verse como elementos funcionales al proceso de inserción de la nación a la economía mundial. La ley es explícita en declarar la optimización y racionalización de la ocupación del territorio como factores potencializadores de la competitividad de las regiones para articularse a los circuitos económicos internacionales. Así lo evidencian los objetivos y estrategias territoriales considerados en el componente general de los POT, dentro de los cuales se enuncia la "identificación y localización de las acciones sobre el territorio que posibiliten organizarlo y adecuarlo para el aprovechamiento de sus ventajas comparativas y su mayor competitividad" (Ley 388/97).

Entendiendo la competitividad como la capacidad de desarrollar una actividad económica exitosa en el nuevo contexto de globalización e internacionalización de la economía (Espinosa y Sánchez, 2001: 460) cabe preguntarse hasta qué punto el Estado colombiano y la política de ordenamiento territorial, en particular, han propiciado condiciones favorables para que las regiones tradicionalmente excluidas del desarrollo nacional sean competitivas en la economía global. La situación es más preocupante si se considera que los factores constitutivos de la llamada competitividad (fortaleza de la economía, intermediación, gobierno, administración privada, infraestructura, ciencia y tecnología, finanzas y recursos humanos) se concentran en las grandes conurbaciones, muy lejos de las cuales se sitúan regiones como la chocoana, cuyo "índice de competitividad" es el más bajo del país (Espinosa y Sánchez: 463).

En las condiciones actuales, la pretensión de orientar la ocupación y explotación del suelo para aprovechar las ventajas comparativas y mejorar la competitividad del municipio no tendrá un resultado distinto a la profundización de las desigualdades regionales. En palabras de Fabio

80 Sandra Patricia Martínez B. 
Velásquez: "La articulación entre lo global y lo territorial puede producir sinergias creativas, pero también fisuras y conflictos desgarradores en el territorio cuando las exigencias del mundo globalizado alimentan procesos de exclusión social" (2001: 37).

\section{Conclusiones}

En la última década, el Pacífico colombiano ha cobrado una importancia creciente en el concierto nacional e internacional. En primer lugar, el auge económico de los países asiáticos de la cuenca del Pacífico ha volcado las miradas hacia esta región como un corredor estratégico para el tránsito de bienes y servicios. En segunda instancia, la aparición de una tendencia conservacionista en el capitalismo y la necesidad de elaborar estrategias de desarrollo alternativo a la sistemática destrucción de la naturaleza, le ha otorgado a las áreas de bosque húmedo tropical una importancia estratégica dentro de la geopolítica mundial.

No menos importante es el nacimiento de identidades étnicas afrocolombianas. Objeto de un atávico proceso de invisibilización, las comunidades negras ganan espacios en la arena política, al punto de lograr el reconocimiento de sus derechos fundamentales en el ámbito constitucional, gracias a la acción organizada de un movimiento social que, en relativamente poco tiempo, ha crecido y se ha fortalecido para hacerse sentir en la vida nacional.
El Pacífico tampoco ha sido ajeno a la geografía de la guerra; se ha convertido en un escenario estratégico de confrontación entre los grupos armados que se disputan el control territorial de la región. Al lado de estos grupos, el narcotráfico hace su aparición, ya sea expandiendo las áreas de cultivos ilícitos o lavando capitales mediante inversiones en proyectos mineros, pesqueros y turísticos.

En el Pacífico confluyen, entonces, múltiples representaciones y prácticas que desde diferentes sectores -capitalistas, planificadores, ecologistas, activistas de movimientos sociales- configuran la región como una espacialidad en conflicto.

Caracterizada como una entidad "desarrollable" sujeta a planes de expansión portuaria, urbana y agroindustrial para adecuarla a los imperativos del desarrollo a escala mundial; como un área de bosque húmedo tropical cuya biodiversidad acusa un enorme potencial económico en términos de la mercantilización de sus recursos naturales; como territorio ancestral de las comunidades negras e indígenas, y como espacio de conflicto entre los grupos armados, la región Pacífica es hoy escenario de profundas transformaciones territoriales.

Paradójicamente, el aporte de los geógrafos a la interpretación de tan compleja realidad espacial ha sido escaso. Con contadas, aunque significativas excepciones, los geógrafos han 
estado prácticamente ausentes de la discusión sobre la reconfiguración territorial que se está dando en regiones como la Pacífica, no solo desde la política oficial de ordenamiento territorial, sino también desde las relaciones cotidianas que los grupos negros e indígenas construyen en el espacio, y que en los últimos años han adquirido estatus político a través de un intenso proceso de reivindicación étnica, donde el territorio deviene en referente central.

Cuando se profundiza en el conocimiento de las categorías geográficas, rápidamente se descubre el valor heurístico de nociones como las de territorio, espacio, lugar, territorialidad y sentido de lugar, para aproximarse a la forma como el ser humano interactúa con el entorno. Advertir la naturaleza geográfica del ser humano permite comprender la forma como el hombre moldea los lugares y, a su vez, cómo estos lugares transformados moldean al ser.

Entre estas categorías, el concepto de lugar reviste una especial importancia, en tanto fuerza que vincula los campos de la naturaleza y la cultura, incluyendo dentro de esta última las relaciones sociales y los significados.

A la luz de estas categorías, se analizó la actual organización espacial del territorio chocoano, en particular de la región del medio Atrato que, como ningún otro lugar, muestra una íntima relación entre un ambiente natural tan exuberante como frágil, el ambiente construido de los asentamientos ribereños y la sociedad negra, que a partir de su evolución histórica y de un intenso intercambio cultural con otros grupos étnicos ha desarrollado creativos mecanismos de adaptación y transformación del medio.

El examen de los sistemas tradicionales de producción, los patrones de asentamiento y las prácticas territoriales que han configurado los lugares culturalmente construidos por las comunidades negras en el curso medio del río Atrato permitió constatar cómo entre estas comunidades predomina una apropiación subjetiva del territorio, caracterizada por un manejo ecológico del entorno y por formas de relación social en las que prima la solidaridad y la reciprocidad, formas que contrastan enormemente con la racionalidad económica y jurídica prevaleciente en el ejercicio de la territorialidad por parte de otros agentes sociales.

Infortunadamente, las territorialidades negras han sido alcanzadas por la lógica del mercado, promovida por sectores empresariales en alianza con agentes estatales, cuyas consecuencias sobre el medio ambiente y la sociedad local han sido devastadoras: degradación de los recursos naturales, crisis de los sistemas tradicionales de producción, altos niveles de dependencia tanto del mercado externo como de los sistemas extractivos minero y forestal, creciente migración de la población

82 Sandra Patricia Martínez B. 
rural hacia los centros urbanos y erosión de las formas de organización social comunitarias.

Se trata, en últimas, de la confrontación entre las relaciones horizontales, de carácter solidario y con un fuerte sentido de arraigo que las comunidades negras han construido en sus espacios cotidianos, y las relaciones verticales y asimétricas introducidas por agentes foráneos, como fuente de dislocación y ruptura socioespacial.

En medio de la degradación del conflicto armado, que en menos de diez años ha logrado desestabilizar las sociedades locales, y de la intensificación del proyecto de neoliberalización en la región, emerge el movimiento social de comunidades negras, precisamente como un espacio de resistencia al proyecto homogeneizante de modernidad propugnado por el Estado y el capital, planteando formas alternativas de pensar el desarrollo, así como nuevos significados y prácticas de organización territorial.

Un proyecto novedoso de ordenamiento territorial, como lo ha sido el proceso de titulación colectiva de territorios negros, no podría estar exento de conflictos en torno a la definición de límites -hasta ahora fundados en la tradición-, a la administración y gestión de los recursos naturales, al ejercicio de nuevas formas de autoridad sin arraigo social entre estas comunidades y a la fijación de fronteras territoriales con los grupos indígenas -antes configuradas como espacios de transición, de uso común entre negros e indios-.

No obstante estas dificultades, los procesos de titulación y administración de las tierras de comunidades negras, definidos a partir de las percepciones y prácticas de apropiación espacial propias, les han permitido a estas comunidades empoderarse del ejercicio de su territorialidad, siendo este apenas el punto de partida del largo camino que estas comunidades emprendieron en la búsqueda de mayores grados de autonomía territorial.

De manera contradictoria, el grado de articulación entre el proceso de reordenamiento territorial agenciado por las comunidades negras y la política oficial de organización espacial ha sido mínimo, fenómeno que puede explicarse, en gran parte, por las limitaciones de una Ley de Desarrollo Territorial que desconoce los mecanismos de apropiación espacial entre negros e indígenas y cuyo determinismo físico y político-administrativo y su marcado énfasis urbano comprometen su aplicabilidad real en una región como la Pacífica.

Para que el ordenamiento territorial conduzca a una ocupación y utilización del territorio compatible con las necesidades e intereses de los grupos negros e indígenas del Pacífico, debe obedecer, antes que a criterios político-administrativos y de incremento de la competitividad regional, a una 
política fundamentada en: la sostenibilidad ambiental y cultural de estas comunidades; el empoderamiento de los Consejos Comunitarios Locales, para agenciar la administración del territorio de acuerdo con su proyecto político y cultural; la innovación en el uso de los ecosistemas, para enfrentar las demandas del futuro a partir de la recreación de las tecnologías tradicionales, y, por encima de todo, la autonomía de estas comunidades para ejercer su territorialidad de acuerdo con sus prácticas consuetudinarias de manejo espacial.

$$
* * *
$$

La investigación aquí referida espera haber sido una contribución a valorar el aporte de las comunidades afrodescendientes en la formación de la nacionalidad colombiana. La aproximación crítica a la política oficial de Ordenamiento Territorial no ha tenido otra pretensión distinta a la de repensar este proceso desde la perspectiva étnica, a partir de la cual es posible plantear formas alternativas al modelo de desarrollo hegemónico e imaginar el ordenamiento territorial mismo.

Cuando se aborda la organización espacial de un territorio determinado, necesariamente se alude a la dimensión geográfica de la existencia humana, que tradicionalmente ha sido relegada de la teoría social, caracterizada por un determinismo historicista en el análisis de los fenómenos sociales. El abordaje del problema del ordenamiento territorial en el país no ha sido la excepción a esta tendencia, ya que poco se ha tenido en cuenta el saber geográfico en la reflexión acerca de este problema, como lo evidencia la ausencia de una discusión sobre el territorio en la Ley 388 de 1997, a tal punto que algunos expertos en el tema han llegado a señalar la Ley de Desarrollo Territorial como la menos territorial de las leyes.

Los capítulos que hacen parte de la investigación constituyen, entonces, un esfuerzo por integrar la perspectiva geográfica en el análisis de la actual organización socioespacial del territorio del Medio Atrato, tomando como referente conceptual el espacio geográfico en sus diferentes escalas e interrelaciones con las dimensiones temporal y social que hacen parte de las determinaciones de existencia del ser humano.

Otro de los aportes del presente trabajo consistió en la recuperación de la tradición oral como fuente válida de conocimiento. El registro testimonial de la visión que tienen los actores involucrados en el problema estudiado permitió contrastar diferentes miradas, así como develar los intereses y expectativas de campesinos, funcionarios públicos y líderes comunitarios en lo que al ordenamiento territorial se refiere. De igual manera, las entrevistas en profundidad con personas conocedoras de la historia local hicieron posible reconstruir parte de

84 Sandra Patricia Martínez B. 
la historia reciente de la región, que carece de fuentes de información, en contraste con la copiosa literatura que se ha escrito sobre los periodos de dominación española y de colonización popular agraria.

El ordenamiento territorial y su relación con las territorialidades étnicas sigue siendo un campo fructífero de investigación. A continuación se sugieren algunas de las situaciones problemáticas derivadas de este tema, cuyo tratamiento no fue posible por sobrepasar los objetivos propuestos en el presente trabajo.

Una primera línea de investigación que puede sugerirse consiste en la evaluación del impacto espacial que ha tenido la implementación de los planes y esquemas de ordenamiento territorial en el departamento. La apertura de espacios de participación en el proceso de formulación de los POT constituye un aspecto fundamental por tener en cuenta a la hora de evaluar el grado de eficacia que ha tenido la planeación territorial sobre una organización del espacio más acorde con los intereses y necesidades de la población.

El proceso de titulación colectiva, derivado de la aplicación de la Ley 70 de 1993, plantea asimismo una serie de interrogantes que requieren de una reflexión tanto desde el ámbito académico como desde las comunidades negras mismas. Si bien es cierto el proceso de adjudicación de tierras a estas comunidades prácticamente ha culminado, quedan todavía importantes situaciones problemáticas por resolver.

En materia de derechos étnico-territoriales, es incierta la situación de los pobladores negros asentados en las áreas urbanas, cuyos rasgos culturales, sistemas productivos y patrones de asentamiento no son tan fácilmente reconocibles, como aquellos que caracterizan a las comunidades negras que habitan en los ríos de la cuenca del Pacífico, sin que por ello tengan menos derecho de acceder a las mismas garantías sociales que les han sido concedidas a estas últimas.

También es incierto el futuro de las comunidades negras rurales cuya autonomía sobre el manejo y administración de los territorios titulados se halla amenazada por diversos factores. En efecto, al momento de promulgarse la Ley 70, ni el conflicto armado ni la proliferación de cultivos ilícitos afectaban de manera tan significativa la región. Diez años después, el Chocó constituye una de las principales zonas expulsoras de población desplazada en el país, como también una de las nuevas áreas de expansión de cultivos ilegales. Frente a la creciente presión ejercida por los grupos armados y los sectores narcotraficantes sobre los territorios de comunidades negras, es difícil esperar que estas decidan autónomamente sobre ellos.

A esto se suma la falta de reglamentación de la mayor parte de los 
capítulos de la Ley 70 , ya que la mera posesión de la tierra no garantiza la supervivencia de estas comunidades, menos si se tiene en cuenta la creciente presión demográfica sobre la tierra, así como la acelerada disminución de la oferta natural. Las comunidades negras enfrentan ahora el reto de elaborar proyectos productivos encaminados a garantizar tanto su seguridad alimentaria como su articulación en condiciones de igualdad a las redes regionales de mercado.

En la misma dirección, es conveniente continuar con el proceso de fortalecimiento político de estas comunidades, ya que, como se tuvo oportunidad de observar, muchos Consejos Comunitarios Locales carecen de legitimidad entre sus comunidades. El fortalecimiento político incluye también al movimiento social de negritudes, que enfrenta el desafío de construir un discurso que recoja las múltiples aspiraciones de un grupo étnico heterogéneo y diverso.

Otra de las líneas de investigación que puede sugerirse tiene que ver con la construcción de propuestas regionales de ordenamiento territorial, que trasciendan las delimitaciones políticoadministrativas dadas por la organización del territorio bajo la forma municipal y departamental. E1 planteamiento de propuestas en este sentido debe ser acorde con las entidades territoriales reconocidas en la Constitución de 1991, cuya reglamentación corresponde a la Ley Orgánica de Ordenamiento Territorial. Cabe anotar que las comunidades negras no han estado ausentes de las discusiones alrededor de la formulación de la Ley Orgánica: la conformación de las Entidades Territoriales Afrocolombianas -ETAes una de sus mayores aspiraciones.

Para terminar, es importante señalar la necesidad de explorar nuevas herramientas metodológicas para el abordaje de este tipo de problemáticas. Las geografías de vida, como una readaptación de la técnica utilizada en los estudios antropológicos -historias de vida-, y el análisis desde la geografía de la percepción, seguramente tienen mucho que aportar al conocimiento de la forma como los afrodescendientes perciben, imaginan y se apropian de su territorio.

86 Sandra Patricia Martínez B. 


\section{Bibliografía}

Aprile-Gniset, Jacques y Gilma Mosquera (1998): Hábitats y sociedades del Pacífico. Cali: Universidad del Valle.

BRAND, Peter et. al. (2001): "Los planes de ordenamiento territorial en Colombia. Una aproximación evaluativa a la implementación de la Ley 388 de 1997". En: Seminario-taller dimensiones territoriales de la guerra y la paz en Colombia. Bogotá: Red de Estudios de Espacio y Territorio.

Colombia. Ministerio del Medio Ambiente (1998): Ley 388 de 1997 por la cual se modifica la Ley 9 de 1989 y la Ley 3 de 1991. Bogotá: El Ministerio.

Espinosa, José y Óscar Sánchez (2001): "La importancia del Ordenamiento Territorial en la integración, la competitividad y el desarrollo”. En: Espacio y territorios. Razón, pasión e imaginarios. Bogotá: Universidad Nacional de Colombia. 725 p.

Instituto Colombiano de la Reforma Agraria -Incora- (2001): Componente de titulación de tierras para comunidades negras. Informe final. Bogotá: Incora.

(2003): Títulos colectivos adjudicados a las comunidades negras. Años 19962003. Bogotá: Incora.

SÁNCHEZ, Joan-Eugeni (1992): Geografía política. Madrid: Síntesis (Colección Espacios y Sociedades - Serie General, Núm. 23). 224 p.

VALENCIA, Emperatriz y July Leesberg (1987):.Los sistemas tradicionales de producción en el Medio Atrato. Quibdó: DIAR-Codechocó, s.p.

VelásqueZ, Fabio (2001): “Ordenamiento Territorial y descentralización. Un paso adelante, dos atrás”. Revista Foro Núm. 41 (julio).

Fecha de recepción: febrero de 2004

Fecha de aprobación: mayo de 2004 
